\title{
A Review of Electroless Gold Deposition Processes
}

\author{
Hassan O. Ali and Ian R.A. Christie \\ GEC Research Laboratories, Hirst Research Centre, Wembley, Middlesex, United Kingdom
}

\begin{abstract}
The literature on electroless gold deposition processes is reviewed both with respect to bath formulation and the kinetics of the electrochemical reduction and oxidation reactions involved. Some modified formulations are discussed in more detail and components processed by the use of electroless gold deposition are illustrated.
\end{abstract}

The application of electroless nickel and copper processes has made a profound impact on the techniques utilized to metallize both conductors and insulators. The printed circuit industry is in fact founded on the ability of electroless copper to cover both insulators and conductors with a uniform thickness of metal; whilst electroless nickel is widely used not only to coat articles of complex geometry but also to impart engineering properties of hardness and wear resistance to parts made of various other metals and alloys.

In the field of gold deposition, especially though not exclusively in the electronics industry, there is a consistent requirement to gold plate complex shapes and electrically isolated tracks and bonding pads. It would be ideal to exploit electroless deposition processes for this purpose. In principle, systems for electroless gold plating should be as easy to operate as those for such deposition of base metals, employing single solutions which have long shelf and working lives, and depositing either pure gold or an alloy of known composition at a reasonable rate of about $5 \mu \mathrm{m} / \mathrm{h}$ or more. In this review it will become clear to the reader that these objectives have not been achieved to date. However, a number of promising systems are currently being developed and a more systematic approach to an understanding of the mechanisms and reactions involved in electroless deposition is emerging. The processes which exist are not considered by the authors to be suitable for continuous production but some processes can be utilized in one-off and small scale applications with consistent success.

\section{Electroless Processes; Definitions}

Because electroless deposition does not involve the passage of externally applied current to the system, some confusion over the use of the term electroless has resulted. Electroless deposition has been used synonymously with chemical deposition which can result from the following processes:

(1) Displacement reactions. Depending on its position in the electrochemical series, a metal higher up in the series may be covered (plated) with the metal lower down in the series. A well known example is the coverage of iron with copper in an acidified copper sulphate solution. Two reactions, one anodic and the other cathodic, take place simultaneously at the surface of the iron.

$$
\begin{aligned}
& \mathrm{Fe} \longrightarrow \mathrm{Fe}^{2+}+2 \mathrm{e} \text { (Anodic) } \mathrm{E}^{\circ}=-0.44 \mathrm{~V} \\
& \mathrm{Cu}^{2+}+2 \mathrm{e} \longrightarrow \mathrm{Cu} \text { (Cathodic) } \mathrm{E}^{\circ}=0.337 \mathrm{~V}
\end{aligned}
$$

Once the iron electrode is fully covered with the thin layer of copper, the process comes effectively to a halt, and no further thickening takes place. The deposit is normally thin $(<1.0 \mu \mathrm{m})$; and its adhesion is not satisfactory.

(2) Galvanic dissolution reactions. In these, the workpiece (M) is coupled to a less noble metal $M_{1}$, and the assembly immersed in the plating solution containing ions $\left(\mathrm{M}_{2}^{\prime+}\right)$ of a more noble metal $M_{2}$. In this case the less noble metal $M_{1}$ goes into solution (anodically) and metal $M_{2}$ deposits onto the workpiece

$$
\begin{aligned}
& \mathrm{M}_{1} \longrightarrow \mathrm{M}_{1}^{\mathrm{n}+}+\mathrm{ne} \\
& \mathrm{M}_{2}^{\mathrm{n}+}+\mathrm{ne} \longrightarrow \mathrm{M}_{2}^{\circ}
\end{aligned}
$$

The metallization in this case can continue for as long as dissolution of the sacrificial anode $\left(M_{l}\right)$ is possible. There are commercially available gold plating solutions which are claimed to produce thicknesses in excess of $2.5 \mu \mathrm{m}$ (1), the preferred substrates being silver, copper, brass, nickel, tin or mild steel coupled to a zinc or aluminium wire. The process is similar, in principle, to contact gilding (2). The donation and acceptance of electrons is an integral part of the above processes - as it is indeed with all aqueous plating processes.

To avoid confusion, it is essential to examine the term electroless deposition. Since electron donation during deposition is essential, we have to rely on methods other than substrate displacement, galvanic dissolution of the sacrificial anode or supply of current via an external power unit (electrodeposition), to achieve this. A chemical 'reducing agent' is the electron donor in all truly electroless plating processes and the process is catalyzed by the deposited metal. Thus, once the substrate surface becomes covered with the plated deposit continuation of the process relies on the latter to catalyze further deposition. The term 'autocatalytic' is therefore used to describe this type of plating. So far, this term has not suffered from the same confusion as the term 'electroless'. Before a gold plating process can be described as autocatalytic an important requirement is therefore that the system in question must be capable of depositing gold on a gold substrate. In the following discussion the terms electroless and autocatalytic will be used interchangeably.

\section{Reasons for Using Electroless Gold}

Unless the workpiece is of non-conducting material or of extremely complex geometry (with deep recesses) it may be better to use conventional electroplating, even if this involves the construction of internal and/or conforming anodes. However, in the production of gold deposits on components which have electrically isolated islands, pads and tracks (for example transistor headers and 
integrated circuits) the use of electroless deposition may be more advantageous.

There are, however, various limitations which characterize electroless gold processes (3), and these are summarized as follows:

(1) Plating rates are low

(2) It is necessary to control plating conditions carefully

(3) Substrates must be thoroughly cleaned

(4) Plating baths tend to have relatively short lives

(5) The thickness distribution of deposits is sensitive to stirring conditions.

Because of these limitations, some of which will be discussed in detail below, it would appear that in order to wartant the use of an electroless gold process, an article must be very specialized, and not amenable to conventional electroplating on an effective or economic basis.

\section{Survey of Known Processes}

A large number of 'electroless' gold plating bath formulations exist in the literature, both in the form of technical papers and patents. Several of these formulations have been reviewed by Okinaka (3). The present authors have tested some of these baths (based on hypophosphite $(4,6)$, hydrazine $(5,7)$, thiourea (8)) and the results wete disappointing. No gold plating was achieved on a gold substrate, and it was concluded that these baths were not autocatalytic. In the case of the thiourea bath (8) we were unable to deposit gold onto a gold substrate despite the claim of Okinaka (3) that it was possible to do so from this solution.

Although the Brookshire hypophosphite bath (9) was not tested by the present authors, it is interesting to note that Okinaka (3) found that the plating of gold on nickel occurred whether hypophosphite was present or absent (though no plating rate was indicated). This is in spite of Brookshire's slaim that hypophosphite was a necessary ingredient, and that decreasing its content reduced the plating rate (see Table I, baths 2 and 5 ). What is more surprising in Brookshire's work is his claim that the plating rate was completely independent of the $\mathrm{pH}$ of the solution (see Table I, baths 1 and 2). The dependence of electroless baths on $\mathrm{pH}$ will be discussed later.

It is beyond the scope of this review to detail all the published electroless gold formulations, but several of these have been listed (Table II) in terms of the gold complex and reducing agents employed. An electroless gold bath which has been widely tried and reported upon in the recent literature is Okinaka's borohydride bath (10). It is therefore worth discussing this in some detail. The bath is an alkaline one, primarily because borohydride undergoes hydrolysis in acid media according to the reaction

$$
\mathrm{BH}_{4}^{-}+2 \mathrm{H}_{2} \mathrm{O} \longrightarrow \mathrm{BO}_{2}^{-}+4 \mathrm{H}_{2}
$$

Thus the $\mathrm{pH}$ is kept as high as possible using potassium hydroxide. However, excess of this reagent was found to be detrimental to the plating rate and the alkali content had to be optimized. Other operating factors such as temperature and concentration had also to be optimized, and three baths were described (Table III).

\section{Table I \\ Electroless Gold Baths Based on Hypophosphite Reducing Agent. After Brookshire (9)}

\begin{tabular}{l|c|c|c|c|c}
\hline & \multicolumn{3}{|c|}{ Bath } \\
Parameter & $(1)$ & $(2)$ & $(3)$ & $(4)$ & $(5)$ \\
\hline Gold cyanide, g/l & 2 & 2 & 20 & 2 & 2 \\
Sodium hypophosphite, g/l & 10 & 10 & 100 & 10 & 1 \\
Potassium cyanide, g/l & 0.2 & 0.2 & 80 & $0.4^{\star}$ & 0.2 \\
Temperature, ${ }^{\circ} \mathrm{C}$ & 96 & 96 & 96 & 96 & 96 \\
$\mathrm{pH}$ & 13.5 & 7.5 & 3.5 & 13.5 & 7.1 \\
Work load, $\mathrm{cm}^{2} / \mathrm{cm}^{3}$ & 0.25 & 0.25 & 0.25 & 0.25 & 0.25 \\
Plating rate, $\mathrm{mg} / \mathrm{cm}^{2} / \mathrm{h}^{\star \star}$ & 9.85 & 9.85 & 12.3 & 8.2 & 3.86
\end{tabular}

*Sodium cyanide used instead of potassium cyanide

${ }^{*} 10 \mathrm{mg} / \mathrm{cm}^{2} / \mathrm{h}$ is approximately $5 \mu \mathrm{m} / \mathrm{h}$, assuming bulk density of gold at $19.3 \mathrm{~g} / \mathrm{cc}$

Plating was found to take place on copper, nickel, cobalt, iron, palladium, platinum, KOVAR, permalloy and steel. It was also reported to occur on gold, thus demonstrating that the process was autocatalytic. The initial stages of deposition on copper and nickel occur by galvanic displacement, and once the basis metal is fully covered with gold further deposition continues by autocatalytic reduction. For this reason the baths would not be suitable for use on very thin (evaporated) films of nickel or copper. Additionally, dissolution of nickel, iron or cobalt was found to lead to premature bath decomposition, and in the case of nickel the rate of deposition was significantly decreased $(29,30)$.

The above electroless gold plating system and the resulting gold deposits have been thoroughly investigated and reported upon by workers at Bell Laboratories (31-37). Their investigations include studies of the properties of the deposits (31), the influence of substrate structure on deposition (32,33) and teplenishment of bath constituents (34). The attractive properties of the electroless deposits were utilized in the metallization of polyvinylidene fluoride films (35), gold plating of groups III-V compound crystals (36) and the manufacture of beam leads (37) on silicon integtated circuits. The handling of silicon wafers required certain precautions, since in highly alkaline solutions silicon dissolves according to the reactions (37):-

$$
\begin{aligned}
& \qquad \mathrm{Si}+6 \mathrm{OH}^{-} \longrightarrow \\
& \mathrm{Si}+4 \mathrm{OH}^{-} \longrightarrow
\end{aligned}
$$

For this reason the portion of the slice (back) which does not 
The Various Combinations of Gold Complexes and Reducing Agents Which Have Been Tested as Potential Electroless Gold Plating Solutlons. The Relevant References (Listed at the End of this Article) are Given.

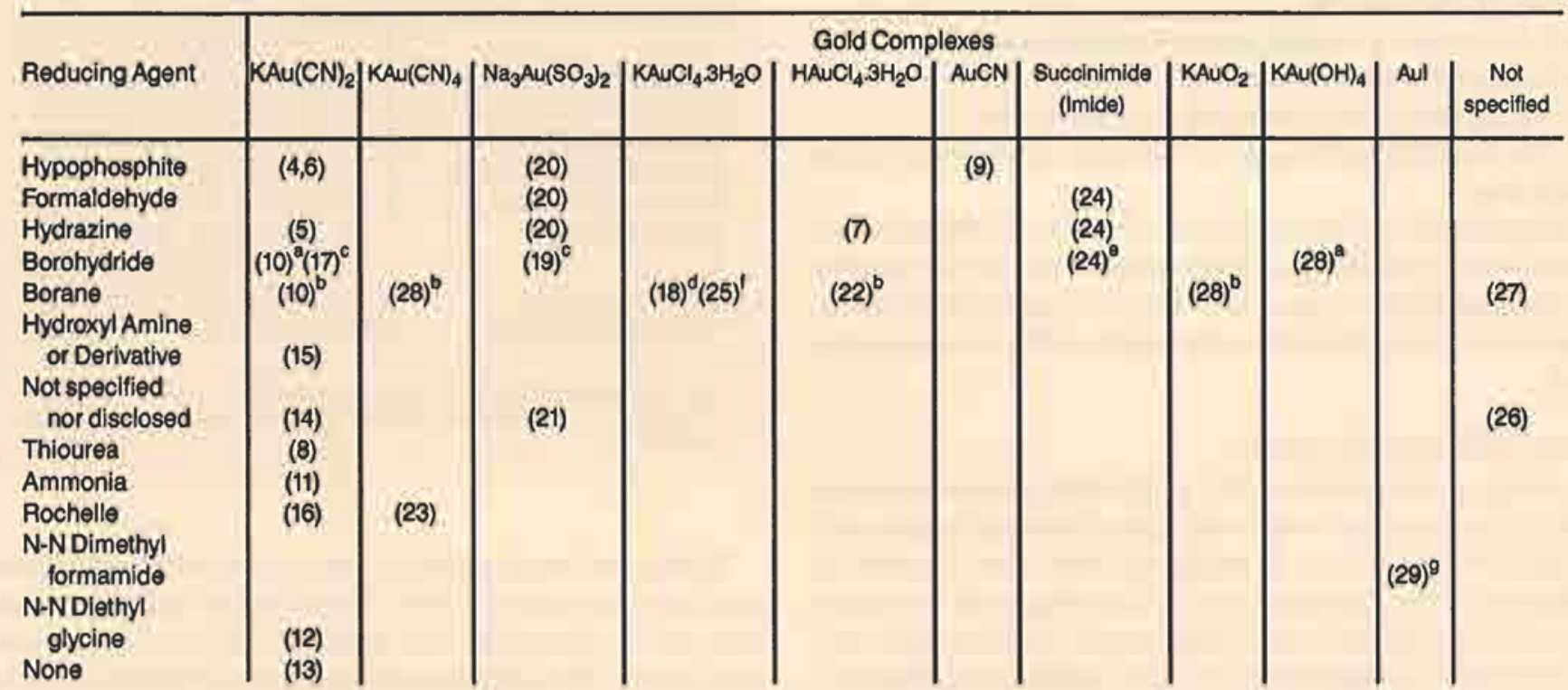

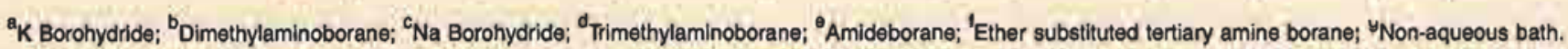

Table III

Electroless Gold Baths Based on Borohydride Reducing Agent. After Okinaka (10)

\begin{tabular}{l|c|c|c}
\hline Parameter & (1) & $\begin{array}{c}\text { Bath } \\
(2)\end{array}$ & $(3)$ \\
\hline Gold potassium cyanide & $0.02 \mathrm{M}(5.8 \mathrm{~g} / \mathrm{l})$ & $0.03 \mathrm{M}(8.6 \mathrm{~g} / \mathrm{l})$ & $0.005 \mathrm{M}(1.45 \mathrm{~g} / \mathrm{l})$ \\
Potassium cyanide & $02 . \mathrm{M}(13 \mathrm{~g} / \mathrm{l})$ & $0.2 \mathrm{M}(13.0 \mathrm{~g} / \mathrm{l})$ & $0.1 \mathrm{M}(6.5 \mathrm{~g} / \mathrm{l})$ \\
Potassium hydroxide & $0.2 \mathrm{M}(11.2 \mathrm{~g} / \mathrm{l})$ & $0.4 \mathrm{M}(22.4 \mathrm{~g} / \mathrm{l})$ & $0.2 \mathrm{M}(11.2 \mathrm{~g} /)$ \\
Potassium borohydride & $0.4 \mathrm{M}(21.6 \mathrm{~g} / \mathrm{l})$ & $0.8 \mathrm{M}(43.1)$ & $0.2 \mathrm{M}(10.8 \mathrm{~g} / \mathrm{l})$ \\
Temperature, ${ }^{\circ} \mathrm{C}$ & 75 & 75 & 75
\end{tabular}

require plating should be properly masked with a material resistant to the plating solution (30). The choice of the masking material is important, since degradation of it leading to the introduction of organics into the bath was found to decrease the plating rate. Polyethylene, for example, was attacked by potassium hydroxide at elevated temperature, and its presence was found to suppress the plating rate (30). It appears that freedom from organic contamination is very important in the preparation of borohydride formulations. Non-uniformity in deposit thickness of as much as 20 to 30 per cent was reported when deionised water was used to prepare the bath. When distilled water, or charcoal-treated deionised water was used, however, this thickness variation was reduced to $<10$ per cent. It will be appreciated from the above that al though borohydride baths can be employed advantageously, they are sensitive to contamination by transition metals or organic materials.

The recent literature contains many patents and technical articles claiming 'successful' electroless gold plating solutions although some of the findings are contradictory. For example, whereas Okinaka's baths (10), as tested by the present authors, appear to be truly autocatalytic, Narayan has (26) dismissed them as being 
immersion baths. Narayan has also described a new neutral bath (without giving details of its make-up) claimed to be capable of a plating rate of up to $7 \mu \mathrm{m} / \mathrm{h}$. The deposit obtained was reported to be pure gold with a Knoop hardness of 140 . This hardness value is nearly twice that obtained by Sard and Okinaka (31,39) (ca. 60-80 Knoop); and is nearer to that of cobalt- or nickel-hardened gold, than it is to that of pure gold. Shazly and Baker have also (27) described a 'high build' electroless gold bath based on a borane complex and potassium hydroxide as well as an undisclosed gold complex. Some similarities are noted between this bath and Okinaka's borohydride bath (10) with respect to trends in the dependence of plating rate on temperature and concentration of ingredients.

Deposits up to $1.0 \mu \mathrm{m}$ exhibited acceptable porosity $(<2$ pores $\left./ \mathrm{cm}^{2}\right)(27)$, this being of the same order as that observed by Sard (31). However, attack by 50 per cent nitric acid on copper and nickel substrates was reported by Dettke $(15)$ to have been prevented with electroless gold deposits as thin as $0.2 \mu \mathrm{m}$.

The properties of electroless gold deposits obtained from borohydride baths (31) have been summarized by Feldstein (39) (Table IV).

\section{Kinetics of Electroless Processes}

In order to develop and improve processes the mechanism of the reactions involved must be understood. An insight into the kinetics of the reactions may assist in predicting the feasibility of a system, although this cannot replace the necessary experimentation to provide the proof of it.

Few studies have been devoted to the kinetics of electroless processes; most of these relate to copper and nickel deposition (40-45) and only one to borohydride gold (29). Brief mention of thermodynamic considerations in electroless nickel processes was made by Barker (46).

In autocatalytic deposition a catalytic substrate is immersed in the plating solution, whereupon the reactions begin simultaneously, and metal is deposited only on the substrate surface (heterogeneous). The deposited metal catalyzes the reaction, causing it to continue autocatalytically. The two most essential components of the plating bath are the metal ions $M^{n+}$ and the reductant $(R e d)$. The plating reaction can be described as follows (47):

$$
\mathrm{M}^{\mathrm{n}+}+\operatorname{Red} \underset{\text { surface }}{\stackrel{\text { catalytic }}{\rightarrow}} \mathrm{M}^{\circ}+\mathrm{Ox}
$$

The oxidation/reduction reaction takes place at the surface of the metal (or metallized) substrate. There the metal ions $M^{n+}$ accept electrons from the reductant $(\operatorname{Re} d)$, and deposit metal film $\left(M^{\circ}\right)$, whilst the reductant, having donated its electrons is converted to its oxidized form $(O x)$. Thus equation 5 can be considered to be a summation of two partial oxidation/reduction reactions
Table IV

Properties of Electroless Gold Deposits. After (39)

\begin{tabular}{l|l}
\hline Property & Value \\
\hline Adhesion & Excellent on metals \\
Appearance & Matt yellow \\
Density & Bulk gold $\left(19.3 \mathrm{~g} / \mathrm{cm}^{3}\right)$ \\
Hardness & Soft (Knoop $60-80)$ \\
Porosity & $\sim$ zero for deposits $>1 \mu \mathrm{m}$ on uniform \\
substrates & $99.9 \%$ \\
Purity & Bulk gold $(0.03$ ohm/square at $1 \mu \mathrm{m})$ \\
Resistivity & Excellent \\
Thermocompression \\
bondability
\end{tabular}$\quad$\begin{tabular}{c} 
Table V \\
\multicolumn{2}{|c|}{ Standard Oxidation-Reduction Potentials. After (48) }
\end{tabular}

\begin{tabular}{c|c|c}
\hline Media & Reaction & $E^{-}, \mathrm{V}$ \\
\hline Alkaline media & $\mathrm{H}_{2} \mathrm{PO}_{2}^{-}+3 \mathrm{OH}^{-}=\mathrm{HPO}_{3}^{2-}+2 \mathrm{H}_{2} \mathrm{O}+2 \mathrm{e}$ & +1.57 \\
& $\mathrm{HCHO}^{-}+3 \mathrm{OH}^{-}=\mathrm{HCOO}^{-}+2 \mathrm{H}_{2} \mathrm{O}+2 \mathrm{e}$ & +1.07 \\
& $\mathrm{BH}_{4}^{-}+8 \mathrm{OH}^{-}=\mathrm{H}_{2} \mathrm{BO}_{3}^{-}+5 \mathrm{H}_{2} \mathrm{O}+8 \mathrm{e}$ & +1.24 \\
Acid media & $\mathrm{H}_{3} \mathrm{PO}_{2}+\mathrm{H}_{2} \mathrm{O}=\mathrm{H}_{3} \mathrm{PO}_{3}+2 \mathrm{H}^{+}+2 \theta$ & +0.50 \\
& $\mathrm{HCHO}_{2} \mathrm{H}_{2} \mathrm{O}=\mathrm{HCOOH}^{+2 \mathrm{H}^{+}+2 \theta}$ & -0.06 \\
\hline Acid $\left(\mathrm{H}_{2} \mathrm{SO}_{4}\right)$ & $\mathrm{Au}^{3+} / \mathrm{Au}$ & +1.5 \\
& $\mathrm{Cu}$ & +0.34 \\
Cyanide & $\mathrm{Au} / \mathrm{Cu}$ & -0.60 \\
complex & $\mathrm{Cu} / \mathrm{Cu}$ & -0.43 \\
& &
\end{tabular}

and

$$
\mathrm{M}^{\mathrm{n}+}+\mathrm{ne} \longrightarrow \mathrm{M}^{\circ} \text { (reduction of metal ions) } 6
$$

Red $-\mathrm{ne} \longrightarrow \mathrm{Ox}$ (oxidation of the reductant)

The equilibrium electrode potentials of the metal $E_{M}\left(M^{n+} / M\right)$ and the reductant $E_{R}(R e d / O x)$ may be obtained using the Nernst equation, and the $E^{\circ}$ (standard oxidation-reduction potential) values. Both potentials depend on solution temperature and ionic concentrations as well as the nature of the complexants employed; whilst the $E_{R}$ value is also strongly affected by the $\mathrm{pH}$ of the solution. Examples of standard oxidation-reduction potentials are given in Table $V$.

The difference between $E_{M}^{\circ}$ and $E_{R}^{\circ}$ (or more correctly $E_{M}$ and $E_{R}$ ) may be used for preliminary screening purposes to determine the effectiveness of various reducing agents. If the difference is too small (or negative), metal reduction may not take place, whilst if it is too large spontaneous decomposition of the solution may occur (50). Since oxidation/reduction reactions take place at the surface of the workpiece (or substrate) the potential at which this occurs lies somewhere between $E_{M}$ and $E_{R}$, and is referred to as the mixed potential $E_{M P}$. The deposition rate resulting from the shift in potential $\left(E_{M} \rightarrow E_{M P}\right)$ has been studied by Paunovic $(40,41)$. The 


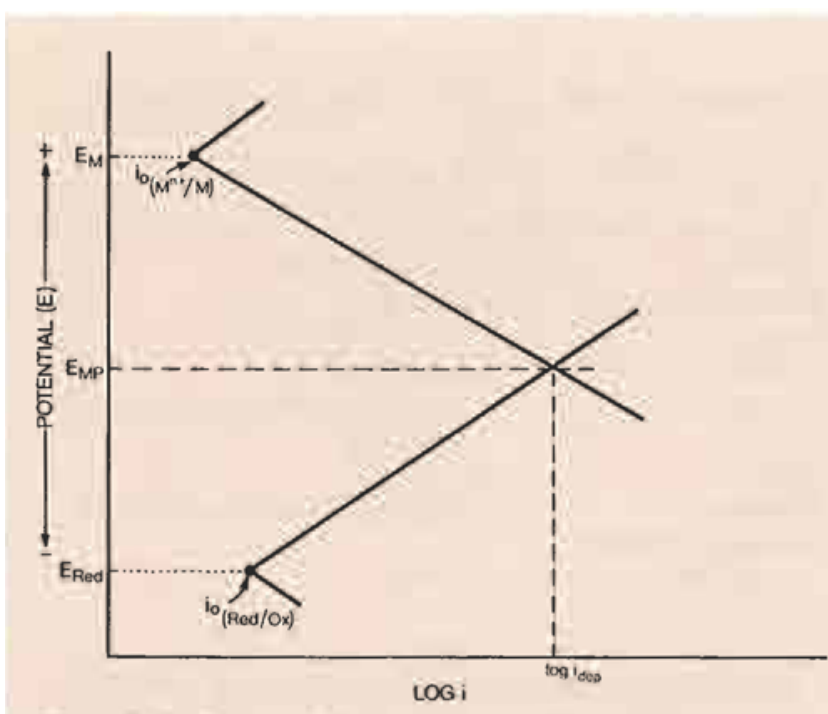

Fig. 1 Schematic potential-current curves showing mixed potential $\mathrm{E}_{\mathrm{MP}}$ and deposition current $i_{\text {dep }}$. At $E_{M P}, i_{\text {anodic }}=i_{\text {cathodic }}=i_{\text {dep }}$. Note that $i_{0}\left(M^{+} / M\right)$ and $i_{0}(\operatorname{Red} / O x)$ are the exchange current densities at the equilibrium potentials $\mathrm{E}_{\mathrm{M}}$ and $\mathrm{E}_{\mathrm{R}}$

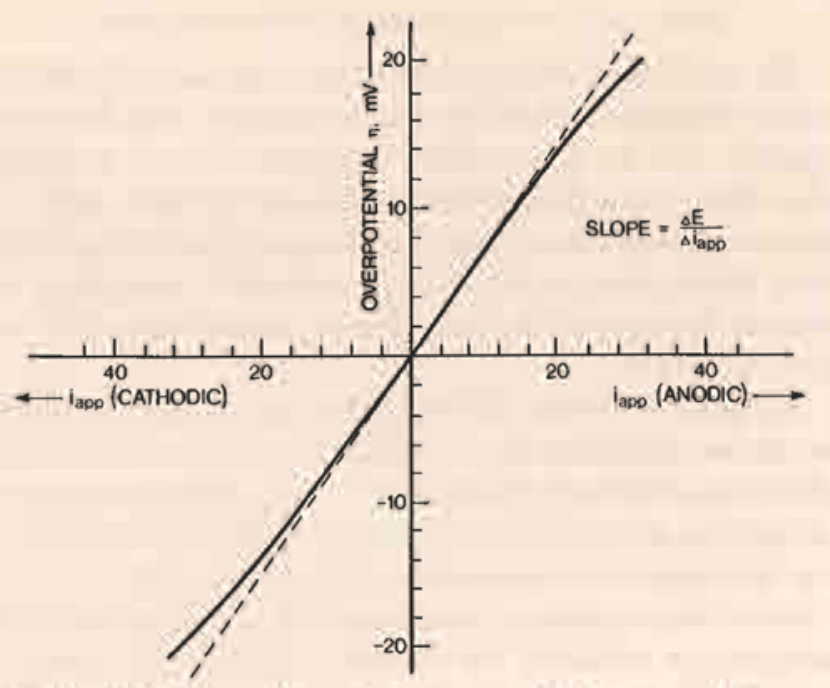

Fig. 2 Applied current linear polarization curve. After Fontana and Greene (51) methods of analysis adopted were similar to those previously applied to corrosion studies (51).

Two techniques may be employed to determine the deposition rate using the mixed potential theory (52). These are the Tafel curve extrapolation (or intersection) technique and the polarization resistance (sometimes called linear polarization) technique. The first technique uses data obtained from anodic and/or cathodic polarization measurements. Where the polarization curve (anodic or cathodic) intercepts the mixed potential $E_{M P}$, the corresponding current $i_{d e p}$ is taken as determining the deposition rate (Figure 1). As can be seen from Figure 1, the anodic and cathodic currents are equal at potential $E_{M P}$ (that is, the rate of reduction of metal ions to metal is equal to the rate of oxidation of the reductant (52)).

The second method (polarization resistance technique), relies on the fact, as observed in corrosion processes, that the applied current density is approximately a linear function of the electrode potential, providing that measurements are kept to within $\pm 10 \mathrm{mV}$ of the mixed potential $E_{M P}$ (Figure 2). However, further kinetic parameters, namely Tafel slopes for the anodic and the cathodic reactions $\left(b_{a}\right.$ and $\left.b_{c}\right)$, must be obtained by some independent method $(54,56)$. Only then can the Stern-Geary (55) equation

be applied.

$$
\frac{\Delta \mathrm{E}}{\Delta \mathrm{I}}=\frac{\mathrm{b}_{\mathrm{a}} \mathrm{b}_{\mathrm{c}}}{2.3 \mathrm{i}_{\mathrm{dcp}}\left(\mathrm{b}_{\mathrm{a}}+\mathrm{b}_{\mathrm{c}}\right)}
$$

Both of these methods were employed by Paunovic $(40,41)$ in studies of the copper/formaldehyde electroless system. Striking correlation was obtained between $i_{\text {dep }}$ and the deposition current $\left(i_{\text {calc }}\right)$ calculated from gravimetric determination of deposition rates. Additional support for Paunovic's findings was recently provided by Sato's coulostatic studies $(42,43)$.

Okinaka (29) applied the intersection method to determine the deposition rate of gold from borohydride baths, and found some correlation between reduction current $\left(i_{c}\right)$ and oxidation current $\left(i_{a}\right), i_{a}$ being approximately equal to $i_{c}$ at the mixed potential $E_{M P}$ (Figure 3, curves 2 and 3 ) for a bath containing $2 \times 10^{-4} \mathrm{M}$ $\mathrm{KAu}(\mathrm{CN})_{2}$. However, for a higher gold concentration $\left(10^{-3} \mathrm{M}\right.$ $\mathrm{KAu}(\mathrm{CN})_{2}$ ) the cathodic current $i_{c}$ was found to be much smaller than the total anodic current $i_{a}$ (Figure 4 , curves 2 and 3 ). This is attributed to the fact that as the $\mathrm{KAu}(\mathrm{CN})_{2}$ content increases, the deposition potential $\left(E_{M P}\right)$ shifts in the positive direction (compare Figures 3 and 4 ), and the contribution of the anodic oxidation current of gold to the total anodic oxidation current becomes significant. Therefore to obtain the anodic current resulting from the contribution of $\mathrm{BH}_{3} \mathrm{OH}^{-}$alone $\left(i_{\mathrm{BH}_{3} \mathrm{OH}}\right)$, the oxidation current of the gold $\left(i_{\text {base }}\right)$ measured in the base electrolyte $(\mathrm{KOH} / \mathrm{KCN})$ must be subtracted from the total anodic current $i_{a}$. However, even after this adjustment it appears that $i_{c} \neq i_{\mathrm{BH}_{3} \mathrm{OH}^{-}}$, and this inequality apparently persists at the higher $\mathrm{KAu}(\mathrm{CN})_{2}$ concentrations studied. Since separate experiments by Okinaka (29) 
show that deposition rates determined gravimetrically are equivalent to $i_{c}$ rather than $i_{\mathrm{BH}_{3} \mathrm{OH}^{-}}$, Okinaka suggested that $\mathrm{Au}(\mathrm{CN})_{2}^{-}$at concentration greater that $10^{-3} \mathrm{M}$ interferes with the anodic oxidation of $\mathrm{BH}_{3} \mathrm{OH}^{-}$, possibly because it adsorbs competitively at the available sites.

It is worth noting that $\mathrm{Ni}(\mathrm{CN})_{4}{ }^{-}$and polyethylene (30) exert a similar effect to that of $\mathrm{Au}(\mathrm{CN})_{2}^{-}$on the oxidation of $\mathrm{BH}_{3} \mathrm{OH}^{-}$, and the resultant poisoning effects led to drastic reduction in the plating rates. This makes it essential that no nickel ions are allowed into the bath, and that organic contaminants are kept to the minimum.

Besides the dependence of the mixed potential $E_{M P}$ on the concentrations of metal ions and reducing agent (44), its value may well be affected by the other experimental parameters of the system $(40,53)$, namely $\mathrm{pH}$, agitation and temperature. For example, as can be seen from Table $\mathrm{V}$, the $\mathrm{pH}$ of the bath has a very strong bearing on the $E^{\circ}$ values of the reducing agent. Consequently, the mixed potential $E_{M P}$ will shift, and $i_{\text {dep }}$ will change accordingly. Indeed Levy (47) reported that the plating rate of nickel from a hydrazine bath increases exponentially with $\mathrm{pH}$ between $\mathrm{pH} 9$ and $\mathrm{pH}$ 11. Shazly and Baker (27) noted a sharp increase in the plating rate of gold from a borane bath from $<0.3 \mu \mathrm{m} / \mathrm{h}$ (at $\mathrm{pH} 12$ ) to 5 $\mu \mathrm{m} / \mathrm{h}$ (at $\mathrm{pH} 13$ ). In view of this it is surprising that Brookshire (9) did not attach any significance to the $\mathrm{pH}$ values of hypophosphite baths (Table I).

Agitation of the electroless solutions seems to exert some inexplicable effects on plating rate. If the deposition rate is governed only by polarization behaviour, and either the anodic or the cathodic (or both) reaction is under diffusion control (Figure 5), then the deposition rate would be expected to increase with solution agitation. In Figure 5(a), where the reduction process is under diffusion control, curves 1 to 6 correspond to limiting diffusion current densities at relative solution velocities ranging from 1 to 6 . The effect of velocity on deposition rate can be seen in Figure 5(b). The deposition rate increases continuously from $A$ to $D$ as the relative velocity is increased from 1 to 4 . However, as the velocity is increased further, the reduction reaction becomes activation controlled, and the deposition rate becomes independent of velocity at very high values. As the velocity is increased from 4 to 6 , the deposition rate remains fixed at point $\mathrm{E}$.

Recent work by Bindra (44) suggests that with rotating electrodes, the mixed potential $E_{M P}$ increases linearly with log (rotation rate $\omega$ ). Additionally $E_{M P}$ was found to vary linearly with $\log C_{M_{\infty}}$ and $\log C_{R_{\infty}}$ where $C_{M \infty}$ and $C_{R_{\infty}}$ are the concentrations of the metal ions and reducing agent in the plating solution. The relevant slopes were found to be inter-related as follows $(57,58)$ :

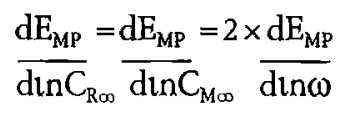

Equation 9 appears to meet the criteria of a diffusion controlled

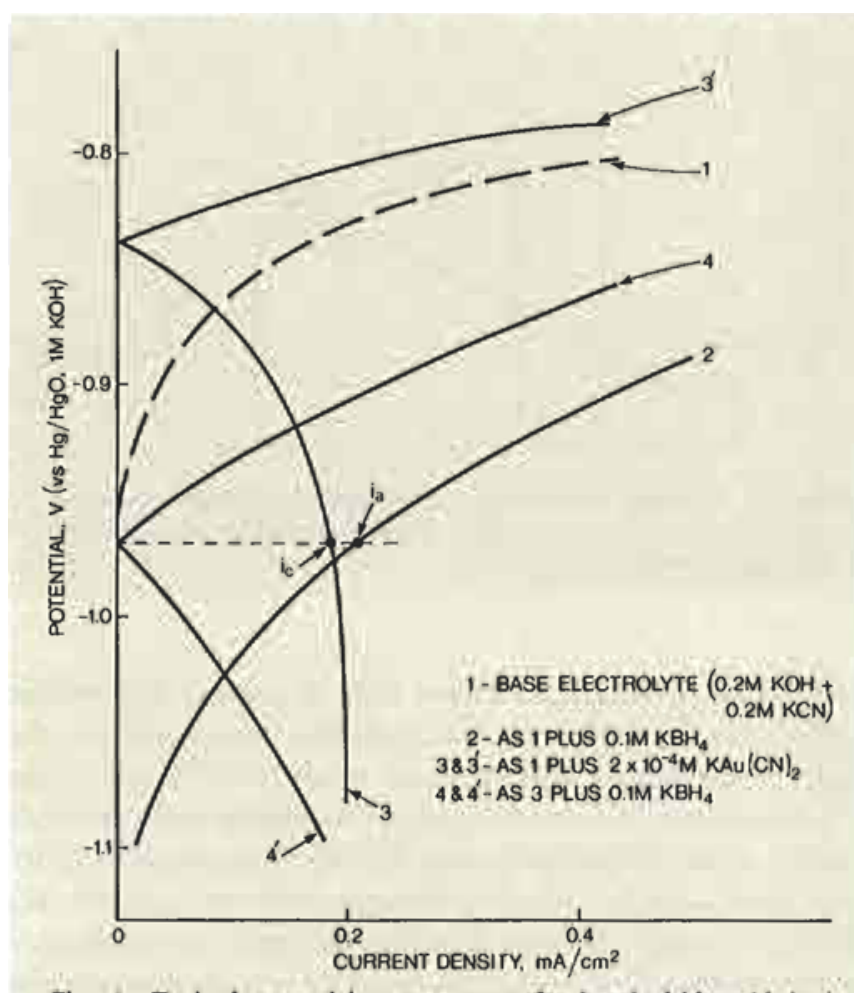

Fig. 3 Derived potential-current curve for borohydride-gold bath containing $2 \times 10^{-4} \mathrm{M} \mathrm{KAu}(\mathrm{CN})_{2}$. After Okinaka (29)

Fig. 4 Derived potential-current curve for botohydride-gold bath containing $1 \times 10^{-3} \mathrm{M} \mathrm{KAu}(\mathrm{CN})_{2}$, After Okinaka (29)

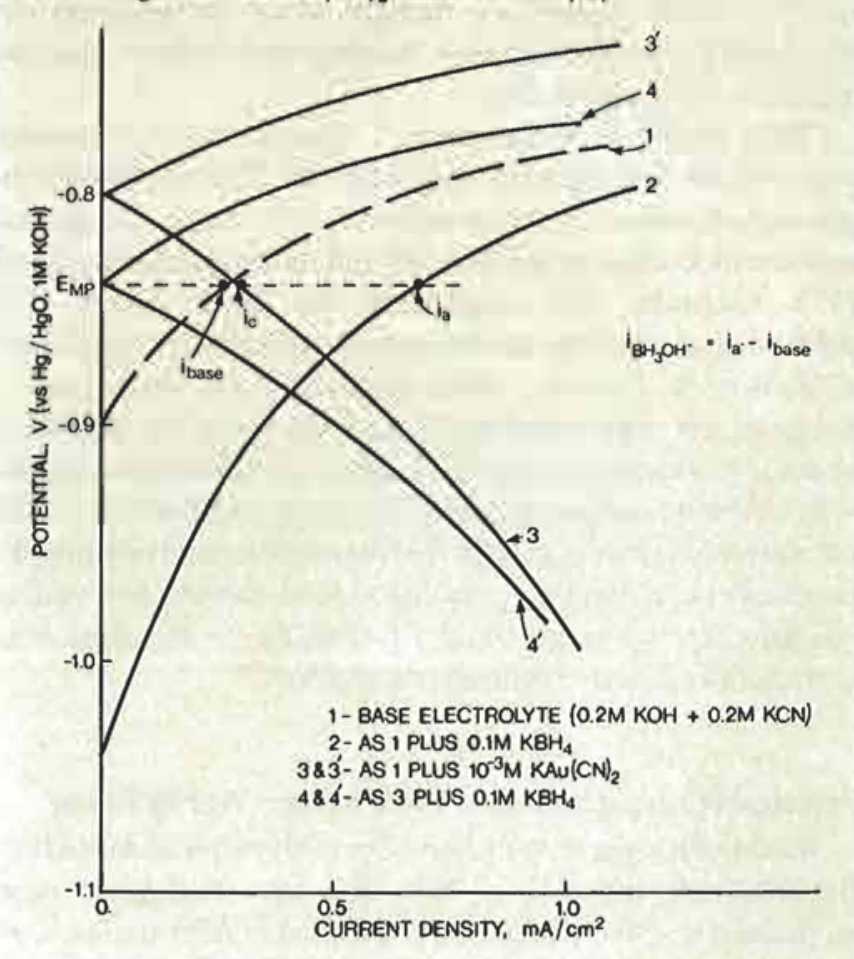




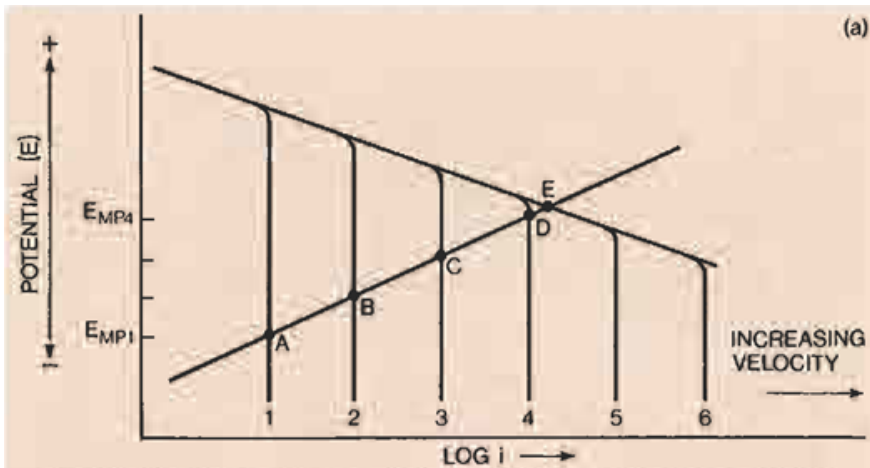

Fig.5(a) Polarization curves, with cathodic current exhibiting concentration polarization, and showing the effect of agitation on mixed potential ( $\left.\mathrm{E}_{\mathrm{MP}}\right)$ and deposition curreat $\left(\mathrm{i}_{\text {dep }}\right)$

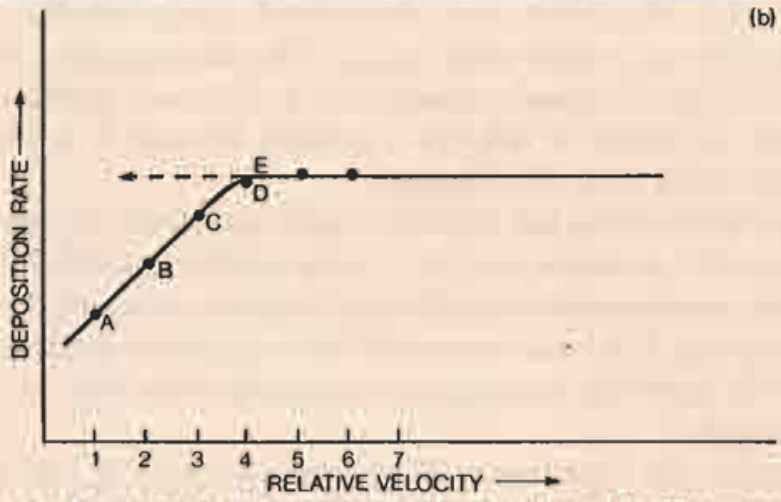

Fig 5(b) The effect of agitation on deposition rate. After Fontana and Greene (29) cathodic partial reaction coupled with an activation controlled partial anodic reaction, a situation pertinent to the copper/formaldehyde system under study (44). Of course the situation may become more complex if either or both electrode reactions have both activation and diffusion control components. The above complex interplay of parameters may explain why Feldstein (59) reported that the deposition rate can be enhanced or impaired by agitation and why the effect of agitation cannot be predicted. Okinaka (10) found that the deposition rate from borohydride gold baths increased linearly with the square root of the rotation rate. As an added advantage improvements in the quality of the deposit are brought about by agitation viz. elimination of nodule formation, lateral growth, uniform grain size and decreased porosity (30).

With regard to temperature it appears that in electroless processes the Arrhenius rate law is followed. Thus doubling of the plating rate is found to occur with every $10^{\circ} \mathrm{C}$ rise in temperature with the nickel/hypophosphite (60) and cobalt/hydrazine systems (47). Okinaka (10) confirmed the above trend with gold/borohydride baths and reported an activation energy of about $19 \mathrm{Kcal} / \mathrm{mole}$. However, decomposition of this bath occurs at temperatures greater than $85^{\circ} \mathrm{C}$, and this limits the maximum operating temperature to $80^{\circ} \mathrm{C}$. A similar trend for deposition rate versus temperature was reported by Shazly and Baker (27). The present authors used data from the latter work for an A rrhenius plot ( $\log \left(\right.$ rate) vs. $\mathrm{T}_{\mathrm{T}}^{-}$), and this yielded a good straight line and an activation energy of about $12.5 \mathrm{Kcal} / \mathrm{mole}$. In this work bath decomposition again occurred at about $85^{\circ} \mathrm{C}$.

\section{Selected Formulations and Their Process Applications}

In addition to the examination of selected systems obtained from the literature the authors have also examined some novel autocatalytic systems based on the available information. One concern in this search was to avoid the necessity of continuous and vigorous agitation, since it is not possible to apply vigorous agitation easily when coating articles of complex geometry.

From these studies two formulations appeared to offer promise in achieving reasonably stable systems which could deposit up to $2 \mu \mathrm{m} / \mathrm{h}$ of gold. In both of these, agitation requirements were minimal with a slow rocking movement of the workpiece being adequate to achieve consistent results as is the case in conventional electroplating procedures. Both processes were found to be truly autocatalytic and most studies were carried out on the deposition of gold onto gold film produced either by electroplating or vacuum deposition.

In the first process examined a palladium complex was introduced into the bath as the reductant. Palladium acetate was considered to be the most suitable palladium complex to employ as this salt is available commercially, and the acetate radical performs a buffering role. The optimized formulation consisted of:

$\begin{array}{ll}\mathrm{KAu}(\mathrm{CN})_{2} & 5 \mathrm{~g} / \mathrm{l} \\ \text { Palladium acetate } & 0.1-1.0 \mathrm{~g} / \mathrm{l} \\ \text { Ethylenediaminetetraacetic acid (EDTA) } & 10-15 \mathrm{~g} / 1 \\ \text { Sodium succinate } & 5-10 \mathrm{~g} / 1 \\ \text { Succinic acid } & 10-15 \mathrm{~g} / 1 \\ \mathrm{pH} & 10.5 \\ \text { Temperature } & 75^{\circ} \mathrm{C}\end{array}$

The deposition rate from the above bath varied with palladium concentration, (Table VI). The deposition rate increased with higher palladium concentrations giving a maximum deposition rate of $1 \mu \mathrm{m} / \mathrm{h}$ for a palladium acetate content of $1 \mathrm{~g} / \mathrm{l}$. The high cost of the palladium salt mitigated against the use of higher palladium contents. The deposit obtained from this solution was smooth, reflecting the substrate contours, and of a matt lemon yellow appearance. The density, as estimated by gravimetric, metallographic and X-ray fluorescence methods was $19.3 \mathrm{~g} / \mathrm{cm}^{3}$ (the density of pure gold) with the major impurity detectable being palladium at between 0.04 and 0.08 per cent by weight. However, the bath was not completely stable and decomposition commenced 


\section{Table VI \\ Effect of Palladium Acetate Content on Deposition Rate and Deposit Purity}

\begin{tabular}{c|c|c|c}
\hline Bath & $\begin{array}{c}\text { Palladium acetate, } \\
\mathrm{g} / \mathrm{l}\end{array}$ & $\begin{array}{c}\text { Deposition rate, } \\
\mu \mathrm{m} / \mathrm{hr}\end{array}$ & $\begin{array}{c}\text { Deposit Pd } \\
\text { content, wt\% }\end{array}$ \\
\hline 1 & 0.1 & 0.2 & 0.04 \\
2 & 0.05 & 0.4 & 0.04 \\
3 & 1.0 & 1.0 & 0.08
\end{tabular}

within approximately 3 h at operating temperatures. Nevertheless, the bath did enable processing to be carried out successfully on a small scale.

The second formulation examined was based essentially upon Okinaka's bath. It was selected from Okinaka's findings (Table III) as being that formulation which required the least agitation to produce a good quality deposit. It consisted of:

$\begin{array}{ll}\mathrm{KAu}(\mathrm{CN})_{2} & 1.45 \mathrm{~g} / 1 \\ \mathrm{KCN} & 6.5 \mathrm{~g} / \mathrm{l} \\ \mathrm{KOH} & 11.2 \mathrm{~g} / 1 \\ \mathrm{KBH}_{4} & 10.8 \mathrm{~g} / 1 \\ \text { Temperature } & 72^{\circ} \mathrm{C}\end{array}$

It was found in practice that, contrary to Okinaka's claim, this bath had a relatively short working life. Within about $1 \mathrm{~h}$ bath decomposition commenced with precipitation of metallic gold. The initial deposition rate of $2 \mu \mathrm{m} / \mathrm{h}$ rapidly decreased with decomposition. Consideration of the formulation suggested that an excess of cyanide to limit dissociation of the gold complex would probably inhibit gold decomposition. With excess cyanide a more stable system was indeed obtained, but at the expense of deposition rate. The further addition of two stabilisers EDTA and ethanolamine appeared to be beneficial in increasing the deposition rate without decreasing bath stability. By an empirical approach a formulation was developed which produced a consistent deposition rate of $1.5 \mu \mathrm{m} / \mathrm{h}$ over the working day of $8 \mathrm{~h}$ duration. Studies indicated that a depletion of the gold content of the bath of up to 50 percent could be tolerated with no significant reduction in gold deposition rate. The oprimized formulation consisted of:

$\begin{array}{ll}\mathrm{KAu}(\mathrm{CN})_{2} & 1.45 \mathrm{~g} / \mathrm{l} \\ \mathrm{KCN} & 11 \mathrm{~g} / 1 \\ \mathrm{KOH} & 11.2 \mathrm{~g} / \mathrm{l} \\ \mathrm{KBH}_{4} & 10.8 \mathrm{~g} / 1 \\ \mathrm{NaEDTA} & 5 \mathrm{~g} / 1 \\ \text { Ethanolamine } & 50 \mathrm{ml} / \mathrm{l}\end{array}$

A bath which had been depleted by some 25 percent of its initial gold content showed no signs of decomposition when stored overnight. When used the next day it produced a constant

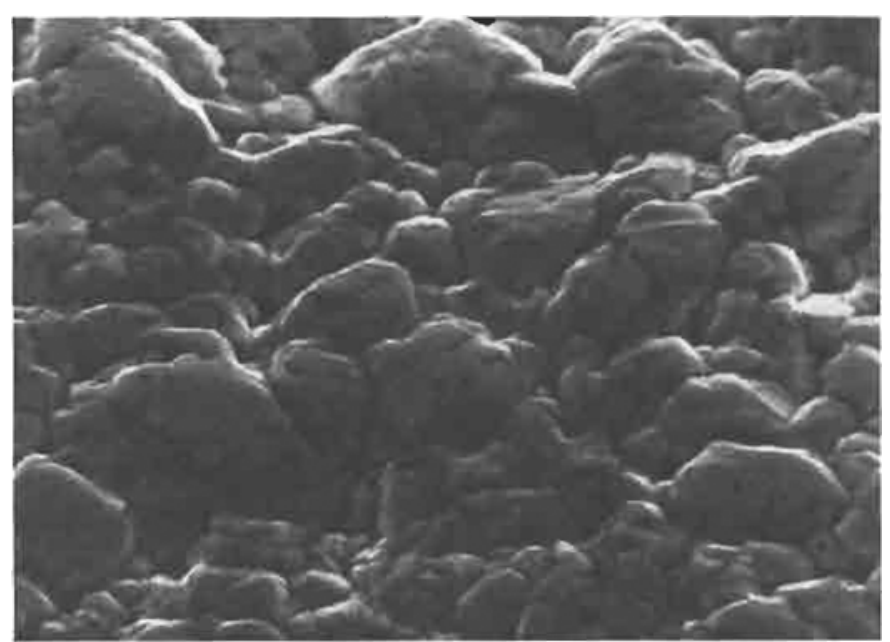

Fig. 6 Scanning electron micrograph of the surface of a $3.5 \mu \mathrm{m}$ thick layer of electroless gold deposited on an alumina substrate which had been previously metallized with $\mathrm{Ti} / \mathrm{Au}$ $\times 5750$

deposition rate of $1 \mu \mathrm{m} / \mathrm{h}$. The reduction in rate is attributed to slow decomposition of the borohydride during storage.

Deposits produced from this formulation, using mild agitation of the workpiece were smooth and soft, with a density of 19.3 $\mathrm{g} / \mathrm{cm}^{3}$. Thermocompression bonds made with the deposit produced sound joints with good adhesion. Morphological studies carried out by scanning electron microscopy (Figure 6), showed a relatively smooth surface and spectrographic analysis of the deposit showed that no significant concentration of impurities was present.

This process has been utilized in the laboratory in two applications:

(1) Production of thick gold tracks and isolated islands on ceramic substrates (Figure 6), a process which may be preferred to using a conventional electroplating process where the more expensive route of premetallizing the whole surface followed by gold electroplating, and subsequent masking and etching is more commonly employed.

(2) Gold metallizing of microwave spiral tracks, in which gold plated isolated copper tracks were required for a microwave device. The starting substrate was a flexible copper laminated board. The conventional technique (Figure 7 (a)) involves photomasking and patterning, gold plating through the resist pattern, removing the resist and etching away the unwanted copper. As can be seen the resultant undercutting, which is aggravated by the galvanic effect at the copper-gold interface, makes this technique undesirable.

The alternative route was to mask the areas which are required, and remove the surrounding copper (Figure 7 (b)). After removal of the resist, a thin layer of gold was applied using the electroless technique. Figure 8 shows part of the electrolessly gold plated component. The advantages of this method were: 

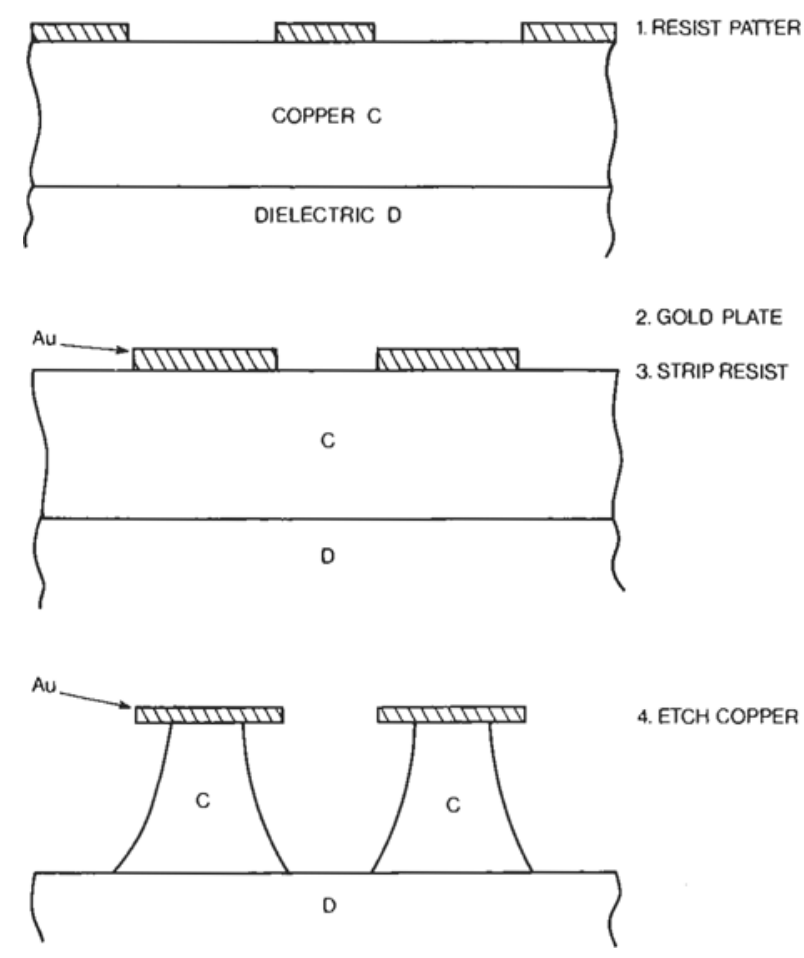

2. GOLO PLATE

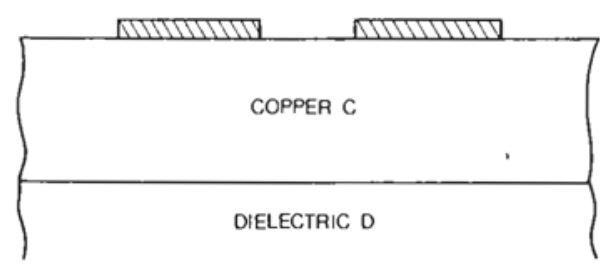

1. RESIST PATTERN
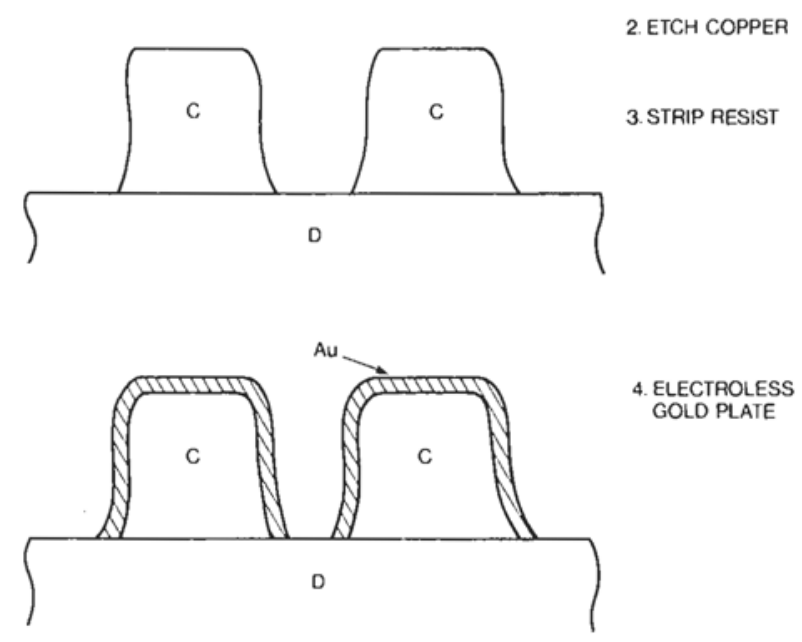

Fig. 7 Sequence for processing spiral tracks, by depositing $2 \mu \mathrm{m}$ of gold on a $15 \mu \mathrm{m}$ copper substrate by:

(a) Conventional electroplating (above left)

(b) Electroless plating (above right)

Fig. 8 Portion of spiral tracks plated with electroless gold

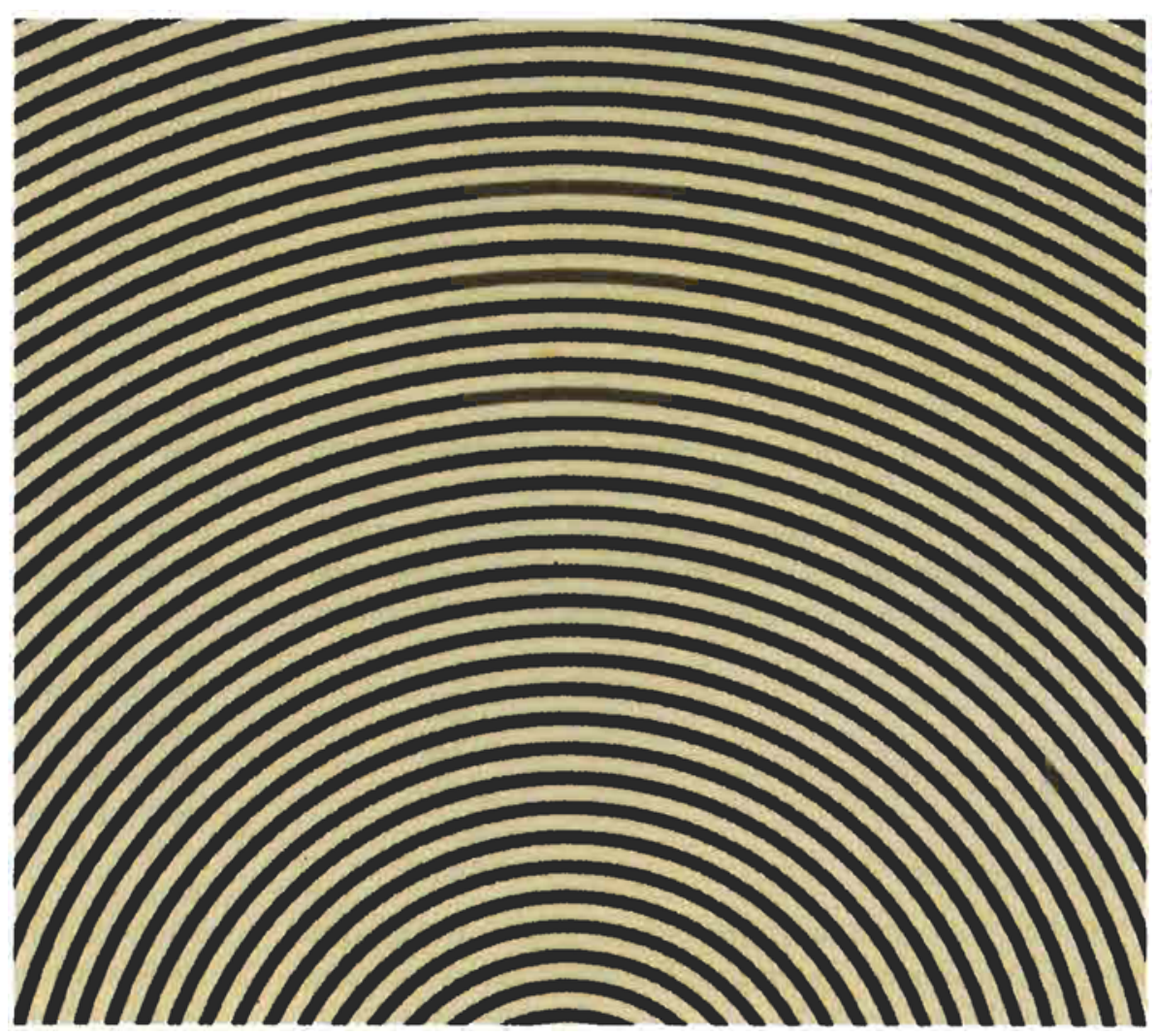

Gold Bull., 1984, 17, (4) 
(i) Excessive copper undercutting was avoided.

(ii) Complete coverage of all the copper was achieved. This is in contrast with technique (a) in Figure 7, where the copper-gold (galvanic) couple may present problems in the presence of even the mildest corrosive atmosphere.

Using the formulation described above a large number of components were gold plated in a routine fashion. This demonstrated that the process was reliable and capable of giving reproducible results in day to day processing. In general the bath was used until 50 per cent of the gold content was consumed and then discarded for reclaim, a fresh bath being produced for the next batch of components.

\section{Summary and Conclusion}

The literature indicates that numerous attempts have been made to define the interdependence of the parameters which affect the performance of electroless deposition systems (concentration, temperature, $\mathrm{pH}$, agitation etc.). These studies have highlighted the problems, but have not made it any easier for the potential user to formulate a gold bath based on theoretical grounds. There is still much research and empirical work to be done before an electroless gold plating bath can be formulated which is reliable and suited for more widespread application than the baths at present available.

However, modifications of the processes developed by Okinaka have been used by the authors of this paper to successfully deposit gold onto components on a batch basis. It is considered that the formulations given are reasonable for many applications, but could not be described as being fully amenable to full scale production work. However, as the techniques for the control and handling of delicate components are becoming more sophisticated this type of batch process could play a significant role in the processing of complex devices. Further work is needed to establish the role played by the individual constituents of the electroless formulation as well as studies aimed at improving both bath life and gold deposition rate. It is hoped that this review, together with the ideas suggested by the authors will assist in the development of practical and commercially viable gold electroless processes.

\section{References}

1 'Galvoric' Immersion Gold Process, Johnson Matthey Chemicals Limited

2 H.M. Habermann, Met., Fintsh, 1946, 44, 525, cited by 'Precious Metal Plating', R. Draper, 1964

3 Y. Okinaka, in 'Gold Plating Technology', edited by F.H. Reid and W. Goldie, Electrochemical Publications, Ayr, Scotland, 1973

4 S.D. Swan and E.L. Gostin, Met. Finish. 1961, 59, (4), 52

5 E.L. Gostin and S.D. Swan, U.S. Pat. 3,032,436 (1962)

6 T. Ezawa and H. Ito, Jpn. Pat. 401081 (1965). See (3)

7 B.M. Luce, U.S. Pat. 3,300,328 (1967)

8 T. Oda and K. Hayashi, U.S. Pat. 3,506,462 (1970)

9 R.R. Brookshire, U.S. Pat, 2,976,181 (1961)

10 Y. Okinaka, Plating, 1970, 57, (9), 914.920

11 F.W. Schneble, J. McCormack and R,J. Zeblisky, U.S. Pat. 3,468,686 (1969)

12 R.F. Walton, J. Electrocbem. Soc., 1961, 108, (8), 767

13 H. Kaestner, Ger. Dem. Rep. Pat. 123813 (1977)

14 V.S. Gromova, N.S. Lyagina, N.A. Smagunovea and T.V. Sharybin, Sov. Pat. SUS49,501 (1977)

15 M. Dettke, L. Stein (Schering A.G.), U.K. Pat $2081309 A$ (1981)

16 Ceramic Systems, Fr: Pat. 2294243 (1976)

17 P. Prost-Tournier and C. Allemmoz, (Engelhard Industries, France), Belg. Pat. $880,030(1980)$

18 J.L. Little, Ger, Pat. 3247144 Al (1983), U.K. Pat. 2114159 (1983)

19 R. Gesemann, F. Richter, L. Gierth, U. Bechtloff andE. Hayer, Ger. Dem. Rep. Pat. DD16 0283 (1983)

20 F. Richter, R. Geseman, L. Gierthand E. Hoyer, Ger. Dem. Rep. Pat. DD15 0762 (981)

21 R. Gesemann, F. Richter, L. Gierth, E. Hoyer and Hartuns, Ger. Dem. Rep. Pat. DD16 $0284 Y(1083)$

22 J.F. McCormack, U.S. Pat. 3,589,916 (1971)

23 R.K. Trueblood, (Ceramic Systems), U.S. Pat. 3,862,850 (1975)

24 K.D. Baker, (Engelhard Minerals and Chemicals Corp.), U.S. Pat. 3,917,855 (1975)

25 A.R. Burke, W.V. Hough, G.T. Hefferan and T. Gerald, U.S. Pat. 4,142,902 (1979)

26 R. Narayan, AES 10th Annual Convention, Indiana

27 M.F. El-Shazly and K. Baker, 'High Build Electroless Gold Process', presented at the 1st AES Electroless Plating Symposium, 25th March, 1982

28 K.D. Baker and M.F. El-Shazly, (Hooker Chemicals and Plastic Corp.), U.K. Pat $2095292 \mathrm{~A}$

29 Y. Okinaka, J. Electrochem. Soc, 1973, 120, (6), 739-744
30 Y. Okinaka, R. Sard, C. Wolowodiuk, W.H. Craft and T.F. Retajczyk, J. Elec trocbem. Soc., 1974, 121, (1), 56-62

31 R. Sard, Y. Okinaka and J.R. Rushton, Plating, 1971, 58, (9), 893-900

32 R. Sard and B.C. Wonsiewicz, J. Electrochem. Soc., 1976, 123, (11), 1604-1612

33 R. Sard, J. Electrochem. Soc. 1970, 117, (9), 1156

34 Y. Okinaka and C. Wolowodiuk, Plating, 1971, 58, (11), 1080-180

35 L.M. Schiavone, J. Electrochem. Soc, 1978, 125, (4), 522-523

36 L.A. D'Asaro and Y. Okinaka, J. Electrocbem. Soc., 1980, 127, (9), 1935-1940

37 R. Sard, Y. Okinaka and H.A. Waggener, J. Electrochem. Soc., 1974, 121, (1), 62-66

38 J.F. Pudvin and FJ. Biondi, in 'Transistor Technology', Vol, III, edited by FJ. Biondi, D. Van Nostrand, Princeton, NJ, 1958. See (37)

39 N. Feldstein, Plating, 1974, 61, (2), 146-153

40 M. Paunovic, Plating, 1968, 55, (11), 1161-1167

41 M. Paunovic and D. Vitkavage, J. Electrochem. Soc., 1979, 126, (12), 2282-2284

42 N. Sato, M. Suzuki and Y. Sato, J. Ilectrochem. Soc, 1983, 130, (7), 1485-1488

43 M. Suzuki, N. Sato, K. Kanno and Y. Sato, J. Electrocbem. Soc., 1982, 129, (10), $2183-2187$

44 P. Bindra and J. Tweedie, J. Electrochem. Soc., 1983, 130, (5), 1112-1114

45 S.M. El-Raghy and A.A. Abo-Salama, J. Electrochem. Soc., 1979, 126, (2), 171-176

46 B.D. Barker, Surf. Technol., 1981, 12,77-88

47 D.J. Levy, in 'Proc. Sth Annual AES Tech. Conf', 1963, pp. 29-36

48 W.M. Latimer, 'Oxidation Potentials', Prentice-Hall, 1952

49 H. Quast, J. Raber, W. Ott, H.G. van Schnering and K. Peters, Ger: Pat, 3148330 (1983)

50 E.B. Saubestre, Metal Finish., 1962, June, 68

51 M.G. Fontana and N.D. Greene, 'Corrosion Engineering', McGraw-Hill, Chapters 9 and 10,1967

52 C. Wagner and Z. Traud, Z. Electrochem., 1938, 44, 434. See (S)

53 W. Rapson and T. Groenwald, Gold Bull., 1975, 8, (4), 119-126

54 F. Mansfield, J. Rlectrocbem. Soc., 1973, 120, (4), 515-518

55 M. Stern and A.L. Geary, J. Electrochem. Soc., 1957, 104, 56

56 R.L. LeRoy, J. Electrocbem. Soc., 1979, 124, (7), 1006-1012

57 V.G. Levich, 'Physicochemical Hydrodynamics', Prentice-Hall, 1962; see (44)

58 A.C. Riddiford, 'Advances in Electrochemistry and Electrochemical Engineering', Vol. IV, Interscience, NY, 1966. See (44)

59 N. Feldstein and P.R. Amodio, Plating, 1969, 56, (11), 1246-1250

60 G. Gutzeit, Plating, 1960, 47, 63 